\title{
Outcomes of the Tryton-dedicated bifurcation stent for the treatment of true coronary bifurcations: Individual-patient- data pooled analysis
}

\author{
Maayan Konigstein $\mathrm{MD}^{1}$ @ | Iva Srdanovic $\mathrm{PhD}^{1}$ | Ankita K. Gore BS $^{2}$ | \\ Hussein M. Rahim $M D^{2}$ | Philippe Généreux $M D^{1,3,4}$ | Ori Ben-Yehuda $M D^{1,2}$ | \\ Indulis Kumsars $\mathrm{MD}^{5}$ | Maciej Lesiak $\mathrm{MD}^{6}$ | Annapoorna Kini MD7 ${ }^{7}$ | Géza Fontos $\mathrm{MD}^{8}$ | \\ Ton Slagboom MD ${ }^{9}$ | Imre Ungi MD, PhD ${ }^{10}$ | D. Christopher Metzger MD ${ }^{11}$ | \\ Aaron Crowley MA ${ }^{1}$ | Martin B. Leon MD ${ }^{1,2}$ | Ziad A. Ali MD, DPhil ${ }^{1,2}$
}

${ }^{1}$ Clinical Trials Center, Cardiovascular Research Foundation, New York, New York

${ }^{2}$ Division of Cardiology, NewYorkPresbyterian Hospital/Columbia University Medical Center, New York, New York

${ }^{3}$ Gagnon Cardiovascular Institute, Morristown Medical Center, Morristown, New Jersey

${ }^{4}$ Hôpital du Sacré-Coeur de Montréal,

Montréal, Québec, Canada

${ }^{5}$ Latvian Center of Cardiology, Paul Stradins Clinical University Hospital, Riga, Latvia

${ }^{6} 1$ st Department of Cardiology, University of Medical Sciences, Poznan, Poland

${ }^{7}$ Mount Sinai Medical Center, New York, New York

${ }^{8}$ Gottsegen Hungarian Institute of Cardiology, Budapest, Hungary

${ }^{9}$ Department of Cardiology, Onze Lieve Vrouwe Gasthuis, Amsterdam, The Netherlands

${ }^{10} 2$ nd Department of Medicine and Cardiology Center, University of Szeged, Szeged, Hungary

${ }^{11}$ Wellmont CVA Heart Institute, Kingsport, Tennessee

Correspondence

Ziad A. Ali, MD, Columbia University Medical Center, Cardiovascular Research Foundation, 1,700 Broadway, 9th Floor, New York, NY 10019.

Email: zaa2112@columbia.edu

\begin{abstract}
Objectives: We aimed to evaluate the safety and efficacy of the dedicated Tryton side branch (SB) stent for the treatment of true bifurcations involving large SBs.

Background: Bifurcation lesions are associated with lower procedural success and a higher risk of adverse cardiac events. Provisional stenting (PS) is currently the default approach for the treatment of bifurcation lesions. The Tryton stent is a dedicated bifurcation stent system for the treatment of true bifurcation lesions.

Methods: We performed an individual-patient-data pooled post-hoc analysis of the Tryton Pivotal randomized controlled trial and post-approval Confirmatory Study. Only patients with true bifurcations involving a $\mathrm{SB} \geq 2.25 \mathrm{~mm}$ in diameter were included. The primary endpoint was non-inferiority of Tryton compared with PS for target vessel failure (TVF) at 1 year.

Results: Of the 411 patients meeting the criteria for enrolment, 287 patients were treated with the Tryton stent and 124 with PS. Procedural success was higher in the Tryton group (95.4 versus $82.3 \%, P<0.0001$ ). TVF at 1 year was $8.1 \%$ in the Tryton group and $9.7 \%$ in the PS group, meeting the pre-specified criteria for non-inferiority established for the randomized controlled trail $\left(p_{\text {non-inferiority }}=0.02\right.$ ). At 9-month angiographic follow-up, SB diameter stenosis was significantly lower in the Tryton group $(29.3 \pm 21.9$ versus $41.1 \pm 17.5, P=0.0008)$ and in-segment binary restenosis (diameter stenosis $\geq 50 \%$ ) was higher in the PS group (19.0 versus $34.2 \%$, respectively, $P=0.052$ ).

Conclusions: In patients with true bifurcations involving a large SB, treatment with the Tryton SD Stent was clinically non-inferior to PS and showed favorable angiographic outcomes.
\end{abstract}

KEYWORDS

angioplasty, bifurcation, drug-eluting stent, percutaneous coronary intervention, provisional

\section{1 | INTRODUCTION}

Percutaneous coronary intervention of bifurcation lesions is technically challenging and is associated with lower procedural success rates and higher risk for adverse cardiac events. ${ }^{1,2}$ Multiple randomized controlled trials (RCTs) have suggested that patients with bifurcation lesions do not benefit from a systematic two-stent strategy, and provisional stenting (PS) has been widely accepted as the gold standard 
for the treatment of most bifurcation lesions. ${ }^{3-7}$ The advantage of the PS strategy has been attributed to less procedure-related myocardial infarction (MI) as well as decreased device-related clinical events at follow-up; ${ }^{1}$ however, PS may require crossover to a second stent in more than one-third of cases, ${ }^{5,8,9}$ with failure to deliver the second stent in approximately $10 \% .{ }^{10}$ Previous RCTs indicating that the PS should be the preferred and default strategy may be limited, as most of them included all bifurcations irrespective of Medina class ${ }^{11}$ or side branch (SB) size. An exception is a study by Hildick-Smith et al. ${ }^{12}$ who showed similar outcomes between PS to Culotte strategy specifically in patients with true bifurcation lesions and large SB. On the other hand, several other studies, including meta-analyses, have recently suggested that a dedicated two-stent strategy is associated with a lower need for revascularization in true bifurcation lesions with large SB, compared with the PS technique ${ }^{1,13}$

We therefore performed an individual-patient-data pooled analysis of the combined data from the Tryton Pivotal RCT and Confirmatory Study to examine the safety and efficacy of the Tryton SB Stent (Tryton Medical, Durham, North Carolina) for the treatment of true bifurcation lesions with $\mathrm{SB} \geq 2.25 \mathrm{~mm}$ by quantitative coronary angiography (QCA) using a contemporary definition of PPMI.

\section{2 | METHODS}

\section{1 | Study population}

Inclusion criteria for the Tryton RCT and Tryton Confirmatory Study were the same and have been described previously. ${ }^{14,15}$ In short, patients with symptoms or objective evidence of ischemia with $a \geq 50 \%$ narrowing in both main branch (MB) and SB with Medina classification 1,1,1; 1,0,1; or $0,1,1^{11}$ (true bifurcation) located in a de novo native coronary artery with an SB 2.5-3.5 mm in diameter and a MB 2.5-4.0 mm in diameter were enrolled. Lesion length was restricted to $\leq 28 \mathrm{~mm}$ in the $\mathrm{MB}$ (treatable with a single stent) and $\leq 5 \mathrm{~mm}$ in the SB. Lesion evaluation was based on visual estimates of the baseline angiography. Important exclusion criteria were (1) ST-segment elevation Ml within $72 \mathrm{hr}$ or non-ST-segment elevation $\mathrm{MI}$ within 7 days preceding the index procedure; (2) left ventricular ejection fraction $<30 \%$; (3) impaired renal function (serum creatinine $>2.5$ $\mathrm{mg} / \mathrm{dL}$ or $>221 \mathrm{mmol} / \mathrm{L}$ ) or current dialysis treatment; (4) left main coronary artery disease (protected or unprotected); (5) trifurcation lesions; (6) a total occlusion of the target vessel (MB or SB); (7) severely calcified lesion(s); (8) the presence of excessive tortuosity; and (9) angiographic evidence of thrombus. Included in this analysis were "lead in" as well as randomized patients from the Tryton Pivotal RCT as long as they had true bifurcation lesions with an SB $\geq 2.25 \mathrm{~mm}$ assessed by QCA ( 2.5 mm per visual estimate) and patients enrolled in the Tryton Confirmatory Study.

\subsection{Study device and procedure}

The Tryton SB Stent is a dedicated bare metal, cobalt chromium, thin strutted SB ostial protection stent mounted on a standard stent delivery balloon. The Tryton has 3 zones: (1) An SB zone (5.5-6.5 mm) to be deployed within the SB; (2) a transition zone $(4.5 \mathrm{~mm})$ to be positioned at the SB ostium; and (3) an MB zone $(8 \mathrm{~mm}) .{ }^{14-16}$
The implantation technique involves lesion preparation (pre-dilation of $\mathrm{MB}$ and $\mathrm{SB}$ ), placement of the bifurcation stent into the SB, and placement of a commercially available DES within the MB. Simultaneous or sequential final kissing balloon (FKB) inflation is then performed. Patients randomized to the provisional $\mathrm{PCl}$ strategy underwent $\mathrm{PCl}$ per standard operator technique, with FKB post-dilation.

\section{3 | Study design}

The TRYTON Pivotal RCT design has been previously described in detail. ${ }^{14}$ Briefly, it was a prospective, multicenter, single-blind RCT that enrolled 704 patients. After completion of the diagnostic angiogram and confirmation of subject eligibility, patients were randomly assigned with the use of a computer-generated scheme, blocked separately at each participating site, and stratified by MB drug-eluting stent use and clinical site.

The Tryton Confirmatory Study ${ }^{15}$ was a prospective, single-arm extension of the Tryton Pivotal RCT that enrolled an additional 133 patients treated with the Tryton and an approved drug-eluting stent in the MB. Both studies were approved by the institutional review board at each participating site, and all patients provided written informed consent.

All serious adverse events were adjudicated by an independent clinical events committee (Harvard Cardiovascular Research Institute, Boston, Massachusetts). A data and safety monitoring board had access to all study data. All data were analyzed by independent consulting biostatisticians. An independent angiographic core laboratory (Cardiovascular Research Foundation, New York, New York) analyzed all angiograms using a conventional single-vessel algorithm analysis. All patients were required to receive dual antiplatelet therapy (unless they developed contraindications) for 12 months. Clinical assessment was performed at 30 days, 9 months, and 12 months post-enrollment.

\section{4 | Study endpoints}

The primary endpoint of this study was the rate of target vessel failure (TVF), defined as the composite of cardiac death, target vessel MI (The Society for Cardiovascular Angiography and Interventions [SCAI] definition ${ }^{17}$ ), and clinically driven target vessel revascularization in the $\mathrm{MB}$ or SB at 1 year. Pre-specified additional clinical secondary endpoints included the following: The rates of device success ( $<30 \%$ residual stenosis within the $\mathrm{SB}$ ), lesion success ( $<50 \%$ residual stenosis using any percutaneous method), and procedural success (lesion success without the occurrence of in-hospital major adverse cardiac events [MACEs; death, MI, emergent coronary artery bypass grafting, clinically driven target lesion revascularization]); the rate of all-cause and cardiac mortality; the rate of Academic Research Consortium-defined stent thrombo$\mathrm{sis}^{18}$ and the rate of target lesion revascularization. The secondary angiographic endpoints were SB in-segment \%DS of the bifurcation stent compared with SB balloon angioplasty and binary restenosis ( $D S \geq 50 \%$ ) of the SB at 9-month angiographic follow-up.

\section{5 | Statistical analysis}

Continuous variables are reported as mean and SD, and compared by the Student $t$ test. Categorical variables are reported as percentage 
TABLE 1 Baseline patient characteristics

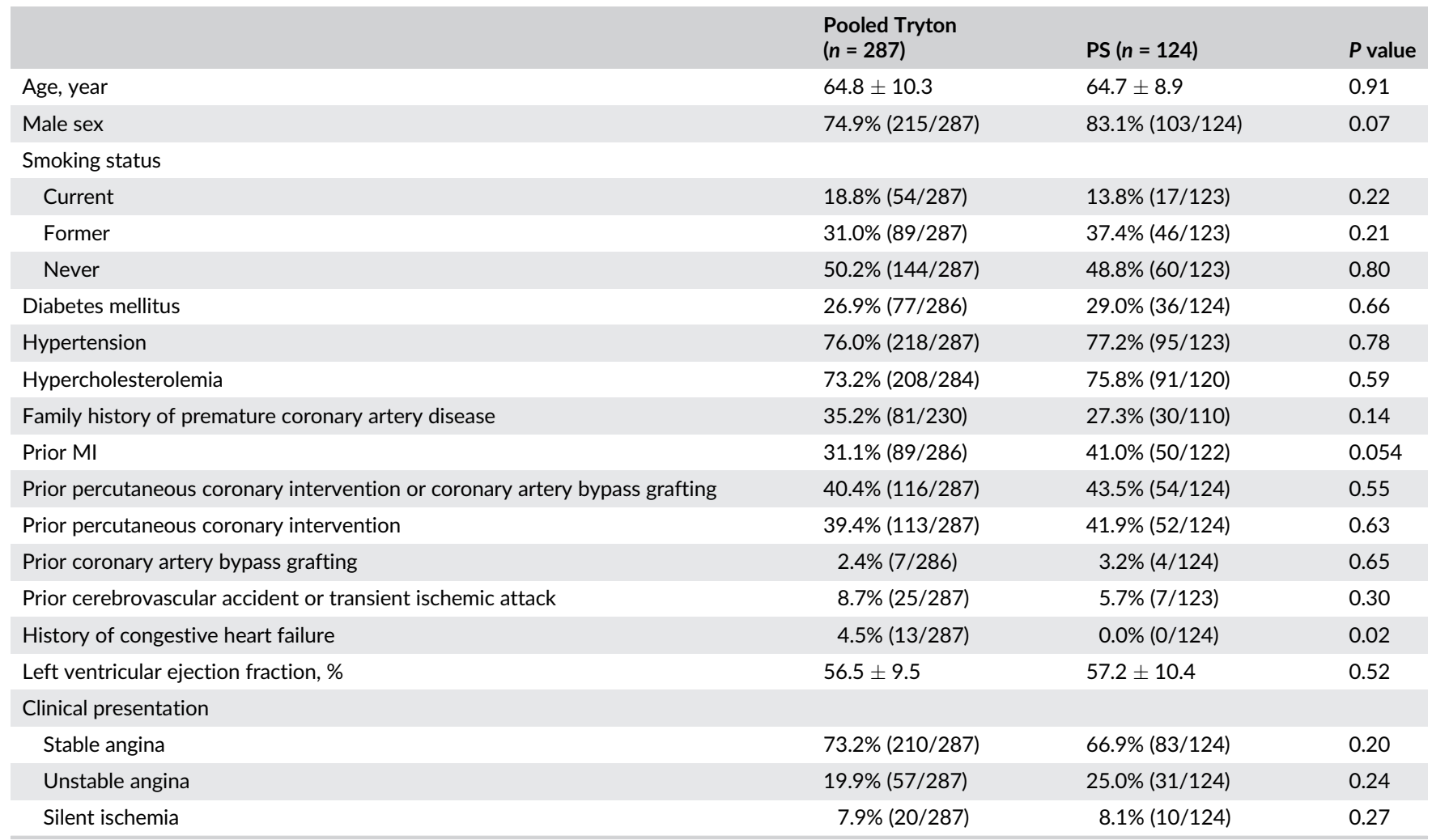

Continuous data are presented as mean \pm SD and dichotomous data as $\%(n / N)$.

and frequency, and compared by the $\chi^{2}$ test or Fisher exact test, as appropriate. Time-to-event variables are reported as Kaplan-Meier failure estimates and number of events, and compared by the log-rank test. The primary endpoint of TVF at 1 year was analyzed using binomial proportions, and the remainder of the endpoints is reported as binary. The differences in event rates between the two treatments arms (Tryton versus PS) were calculated along with a two-sided 95\% $\mathrm{Cl}$ of the difference. The $\mathrm{Cl}$ was calculated by the Z-test with continuity correction. If the upper bound of this $\mathrm{Cl}$ is $<5.5 \%$ (the pre-specified non-inferiority margin), then we declare that Tryton is non-inferior to PS with respect to the primary endpoint. Analysis of the primary endpoint was performed on subjects with $365 \pm 30$ days of follow-up or an adjudicated event. All tests were two-sided, and $P<0.05$ was considered statistically significant. Statistical analyses were performed with SAS version 9.4 (SAS Institute, Cary, North Carolina).

\section{3 | RESULTS}

\section{1 | Patient and procedures}

A total of 902 patients were enrolled to the Tryton studies, of those, 411 (45.6\%) patients fulfilled the entry criteria for this analysis: 287 patients treated with the Tryton SB Stent (155 RCT and 132 confirmatory study) and 124 patients randomized to PS from the RCT. Baseline clinical characteristics of the study population according to treatment are presented in Table 1. Baseline clinical characteristics were similar between treatment groups.
Procedural characteristics are presented in Table 2. Procedure duration, fluoroscopy duration, and use of contrast media and lesion preparation was greater in the Tryton group than in the PS group. The Tryton stent was successfully delivered in 98.3\% (282/287) of cases, and FKB inflation was performed more frequently in the Tryton group (97.2 versus $91.9 \%, p=.02$ ).

Angiographic characteristics and results are presented in Table 3. There were no differences in $\mathrm{PCl}$ location, Medina classification, or $M B$ angiographic findings. In the SB, the baseline \%DS was greater in the Tryton group $(61.6 \pm 12.1$ versus $57.5 \pm 10.8 \%, P=0.001)$. Post-PCI the residual MB minimum lumen diameter (MLD) was similar, but \%DS was higher in the Tryton group compared with the PS group ( $11 \pm 7.9$ versus $9.1 \pm 7.3 \%, P=0.02$ ), while in the SB both the MLD $(2.3 \pm 0.32$ versus $1.7 \pm 0.5 \%, P<0.0001)$ and residual DS $(11.2 \pm$ 8.7 versus $32.4 \pm 18.2 \%, P<0.0001)$ were improved in the Tryton group. Correspondingly, device success ( $<30 \%$ DS in SB), lesion success $(<50 \%$ DS in SB), and procedural success $(<50 \%$ DS in SB without in-hospital MACE) were significantly higher in the Tryton group compared with the PS group.

\subsection{Clinical outcomes}

There was no difference in TVF (3.1 versus $2.4 \%, P=0.69$ ), TLF (3.1 versus $2.4 \%, P=0.69$ ), MACE (4.2 versus $2.4 \%, P=0.38$ ), or their respective individual components 30 days post-procedure between the Tryton and PS groups (Table 4). Similarly, there was no difference in TVF (8.1 versus 9.7\%, $P=0.61$ ) (Figure 1), TLF (8.1 versus $8.1 \%, P=0.97$ ), MACE (10.9 versus $9.7 \%, P=0.70$ ), or their respective individual components 1 -year post-procedure between 
TABLE 2 Procedural characteristics

\begin{tabular}{|c|c|c|c|}
\hline & $\begin{array}{l}\text { Pooled Tryton } \\
(n=287)\end{array}$ & PS $(n=124)$ & $P$ value \\
\hline $\begin{array}{l}\text { Procedure duration, } \\
\min \end{array}$ & $68.6 \pm 32.4$ & $56.6 \pm 27.4$ & 0.0004 \\
\hline \multicolumn{4}{|l|}{ Access site } \\
\hline Femoral & $60.3 \%(173 / 287)$ & $59.7 \%(74 / 124)$ & 0.91 \\
\hline Radial & $39.4 \%(113 / 287)$ & $40.3 \%(50 / 124)$ & 0.86 \\
\hline $\begin{array}{l}\text { Fluoroscopy duration, } \\
\text { min }\end{array}$ & $24.3 \pm 13.7$ & $18.8 \pm 11.9$ & 0.0002 \\
\hline Contrast volume, $\mathrm{mL}$ & $261.3 \pm 100.9$ & $231.1 \pm 89.2$ & 0.004 \\
\hline $\begin{array}{l}\text { Pre-dilation of the } \\
\text { main vessel }\end{array}$ & $90.9 \%(260 / 286)$ & $79.8 \%(99 / 124)$ & 0.002 \\
\hline Pre-dilation of the SB & $96.9 \%(278 / 287)$ & $63.6 \%(77 / 121)$ & $<0.0001$ \\
\hline $\begin{array}{l}\text { Tryton stent } \\
\text { successfully } \\
\text { delivered }\end{array}$ & $98.3 \%(282 / 287)$ & $0.8 \%(1 / 124)$ & \\
\hline $2.5 / 2.5 \times 19 \mathrm{~mm}$ & $6.4 \%(18 / 282)$ & $0.0 \%(0 / 1)$ & \\
\hline $3.0 / 2.5 \times 19 \mathrm{~mm}$ & $36.5 \%(103 / 282)$ & $0.0 \%(0 / 1)$ & \\
\hline $3.5 / 2.5 \times 19 \mathrm{~mm}$ & $30.1 \%(85 / 282)$ & $100.0 \%(1 / 1)$ & \\
\hline $3.5 / 3.0 \times 18 \mathrm{~mm}$ & $25.2 \%(71 / 282)$ & $0.0 \%(0 / 1)$ & \\
\hline $4.0 / 3.5 \times 18 \mathrm{~mm}$ & $1.8 \%(5 / 282)$ & $0.0 \%(0 / 1)$ & \\
\hline \multicolumn{4}{|l|}{$\begin{array}{l}\text { Drug-eluting stent } \\
\text { type }\end{array}$} \\
\hline $\begin{array}{l}\text { Everolimus-eluting } \\
\text { XIENCE }\end{array}$ & $49.5 \%(141 / 285)$ & $53.2 \%(66 / 124)$ & 0.49 \\
\hline $\begin{array}{l}\text { Everolimus-eluting } \\
\text { PROMUS }\end{array}$ & $29.5 \%(84 / 285)$ & $36.3 \%(45 / 124)$ & 0.17 \\
\hline $\begin{array}{l}\text { Zotarolimus-eluting } \\
\text { resolute }\end{array}$ & $7.4 \%(21 / 285)$ & $3.2 \%(4 / 124)$ & 0.11 \\
\hline $\begin{array}{l}\text { Zotarolimus-eluting } \\
\text { endeavor }\end{array}$ & $2.5 \%(7 / 285)$ & $2.4 \%(3 / 124)$ & 0.98 \\
\hline $\begin{array}{l}\text { Sirolimus-eluting } \\
\text { CIPHER }\end{array}$ & $3.5 \%(10 / 285)$ & $4.8 \%(6 / 124)$ & 0.52 \\
\hline Other & $7.7 \%(22 / 285)$ & $0.0 \%(0 / 124)$ & 0.001 \\
\hline Stent diameter & $3.17 \pm 0.35$ & $3.13 \pm 0.36$ & 0.20 \\
\hline FKB & $97.2 \%(279 / 287)$ & $91.9 \%(114 / 124)$ & 0.02 \\
\hline SB stenting & $2.1 \%(6 / 287)^{a}$ & $8.9 \%(11 / 124)$ & 0.002 \\
\hline
\end{tabular}

Continuous data are presented as mean \pm SD and dichotomous data as \% $(n / N)$.

a Bailout stenting.

the Tryton and PS groups. The Tryton was non-inferior to PS for TVF at 1 year $\left(p_{\text {non-inferiority }}=0.02\right)$.

\section{3 | Angiographic outcomes}

A total of 132 patients (59 patients from the Tryton group and 73 patients from the PS group) underwent angiographic follow-up at 9 months. In the MB, reference vessel diameter and MLD were larger in the Tryton group; however, there was no difference in DS (13.6 \pm 11.7 versus $15.0 \pm 11.9 \%, P=0.49$ ) or in-segment binary restenosis (8.5 versus $9.6 \% P=0.82$ ) between groups (Table 5 ). In the SB, reference vessel diameter was similar; however, in-segment MLD (1.75 \pm 0.56 versus $1.44 \pm 0.42, P=0.0004)$, DS $(29.3 \pm 21.9$ versus $41.1 \pm$ $17.5 \%, P=0.0008$ ), and in-segment binary restenosis (19.0 versus $34.2 \%, P=0.052$ ) all favored the Tryton group compared with the PS group.
TABLE 3 Angiographic core laboratory assessed characteristics and results

\begin{tabular}{|c|c|c|c|}
\hline & $\begin{array}{l}\text { Pooled Tryton } \\
(n=287)\end{array}$ & PS $(n=124)$ & $P$ value \\
\hline \multicolumn{4}{|l|}{ Baseline } \\
\hline \multicolumn{4}{|l|}{ Vessel location } \\
\hline $\begin{array}{l}\text { Left anterior } \\
\text { descending }\end{array}$ & $72.5 \%(208 / 287)$ & $68.5 \%(85 / 124)$ & 0.42 \\
\hline Left circumflex & $19.9 \%(57 / 287)$ & $22.6 \%(28 / 124)$ & 0.53 \\
\hline Right & $7.3 \%(21 / 287)$ & $8.9 \%(11 / 124)$ & 0.59 \\
\hline Left main & $0.3 \%(1 / 287)$ & $0.0 \%(0 / 124)$ & 0.51 \\
\hline \multicolumn{4}{|l|}{ Medina classification } \\
\hline $1,1,1$ & $53.0 \%(152 / 287)$ & $46.0 \%(57 / 124)$ & 0.19 \\
\hline $1,0,1$ & $17.1 \%(49 / 287)$ & $19.4 \%(24 / 124)$ & 0.58 \\
\hline $0,1,1$ & $30.0 \%(86 / 287)$ & $34.7 \%(43 / 124)$ & 0.34 \\
\hline \multicolumn{4}{|l|}{ MB } \\
\hline Lesions length, mm & $16.5 \pm 7.3$ & $15.9 \pm 6.6$ & 0.44 \\
\hline Severe tortuosity & $0.7 \%(2 / 287)$ & $1.6 \%(2 / 124)$ & 0.39 \\
\hline Severe calcification & $6.6 \%(19 / 287)$ & $4.0 \%(5 / 124)$ & 0.30 \\
\hline $\begin{array}{l}\text { Reference vessel } \\
\text { diameter, mm }\end{array}$ & $3.09 \pm 0.37$ & $3.06 \pm 0.33$ & 0.40 \\
\hline Diameter stenosis, \% & $67.58 \pm 10.92$ & $66.46 \pm 10.94$ & 0.34 \\
\hline \multicolumn{4}{|l|}{ SB } \\
\hline $\begin{array}{l}\text { Reference vessel } \\
\text { diameter, } \mathrm{mm}\end{array}$ & $2.51 \pm 0.21$ & $2.52 \pm 0.22$ & 0.52 \\
\hline Diameter stenosis, \% & $61.64 \pm 12.10$ & $57.53 \pm 10.84$ & 0.001 \\
\hline \multicolumn{4}{|c|}{ Post-percutaneous coronary intervention } \\
\hline \multicolumn{4}{|l|}{ MB } \\
\hline In-stent MLD, mm & $2.8 \pm 0.39$ & $2.8 \pm 0.33$ & 0.86 \\
\hline $\begin{array}{l}\text { In-stent diameter } \\
\text { stenosis, \% }\end{array}$ & $11 \pm 7.93$ & $9.07 \pm 7.32$ & 0.02 \\
\hline \multicolumn{4}{|l|}{ SB } \\
\hline $\begin{array}{l}\text { In-segment } \\
\text { MLD, mm }\end{array}$ & $2.29 \pm 0.32$ & $1.71 \pm 0.47$ & $<0.0001$ \\
\hline $\begin{array}{l}\text { In-segment } \\
\text { diameter } \\
\text { stenosis, \% }\end{array}$ & $11.23 \pm 8.70$ & $32.37 \pm 18.16$ & $<0.0001$ \\
\hline Device success & $98.2 \%(280 / 285)$ & $43.5 \%(54 / 124)$ & $<0.0001$ \\
\hline Lesion success & $98.9 \%(282 / 285)$ & $83.9 \%(104 / 124)$ & $<0.0001$ \\
\hline $\begin{array}{c}\text { Procedural } \\
\text { success }\end{array}$ & $95.4 \%(272 / 285)$ & $82.3 \%(102 / 124)$ & $<0.0001$ \\
\hline
\end{tabular}

Continuous data are presented as mean \pm SD and dichotomous data as \% $(n / N)$.

\section{4 | DISCUSSION}

In this post-hoc analysis of the TRYTON Pivotal RCT and Tryton Confirmatory Study, we aimed to investigate the safety and efficacy of the Tryton compared with PS for the treatment of patients with true bifurcation lesions involving a large SB ( $\geq 2.25 \mathrm{~mm}$ by QCA). We report the following important findings: (1) Bifurcation stenting using the Tryton is highly feasible, with success in $98 \%$ of bifurcation lesions attempted and with minimal increases in procedure duration, fluoroscopy, and contrast use. (2) In true bifurcation lesions, despite tighter stenoses at baseline, the Tryton SB Stent led to improved MLD, insegment DS, device success, lesion success, and procedural success compared with PS immediately post-PCI. (3) There were no 
TABLE 4 Clinical outcomes

\begin{tabular}{|c|c|c|c|}
\hline & $\begin{array}{l}\text { Pooled } \\
\text { Tryton } \\
(n=287)\end{array}$ & $\begin{array}{l}\text { PS } \\
(n=124)\end{array}$ & $P$ value \\
\hline \multicolumn{4}{|l|}{30 days } \\
\hline TVF & $3.1 \%(9)$ & $2.4 \%(3)$ & 0.69 \\
\hline MACES & $4.2 \%(12)$ & $2.4 \%(3)$ & 0.38 \\
\hline Death & $0.0 \%(0)$ & $0.0 \%(0)$ & - \\
\hline Cardiac & $0.0 \%(1)$ & $0.0 \%(0)$ & - \\
\hline Target vessel MI & $2.8 \%(8)$ & $2.4 \%(3)$ & 0.83 \\
\hline Periprocedural MI & $2.4 \%(7)$ & $2.4 \%(3)$ & 0.99 \\
\hline Any MI & $3.5 \%(10)$ & $2.4 \%(3)$ & 0.57 \\
\hline Target vessel revascularization & $1.4 \%(4)$ & $0.0 \%(0)$ & 0.19 \\
\hline Target lesion failure & $3.1 \%(9)$ & $2.4 \%(3)$ & 0.69 \\
\hline $\begin{array}{l}\text { Emergent coronary } \\
\text { artery bypass grafting }\end{array}$ & $0.3 \%(1)$ & $0.0 \%(0)$ & 0.51 \\
\hline Target lesion revascularization & $1.4 \%(4)$ & $0.0 \%(0)$ & 0.19 \\
\hline Stent thrombosis & $1.4 \%(4)$ & $0.0 \%(0)$ & 0.19 \\
\hline \multicolumn{4}{|l|}{1 year } \\
\hline TVF & $8.1 \%(23)$ & $9.7 \%(12)$ & 0.61 \\
\hline MACES & $10.9 \%(31)$ & $9.7 \%(12)$ & 0.70 \\
\hline Death & $2.1 \%(6)$ & $0.8 \%(1)$ & 0.35 \\
\hline Cardiac death & $0.4 \%(1)$ & $0.0 \%(0)$ & 0.50 \\
\hline Target vessel MI & $3.1 \%(9)$ & $2.4 \%(3)$ & 0.69 \\
\hline Any MI & $4.2 \%(12)$ & $3.2 \%(4)$ & 0.64 \\
\hline Target vessel revascularization & $6.8 \%(19)$ & $7.3 \%(9)$ & 0.87 \\
\hline MB & $3.9 \%(11)$ & $5.7 \%(7)$ & 0.44 \\
\hline SB & $4.3 \%(12)$ & $2.4 \%(3)$ & 0.37 \\
\hline Target lesion failure & $8.1 \%(23)$ & $8.1 \%(10)$ & 0.97 \\
\hline Target lesion revascularization & $6.0 \%(17)$ & $5.7 \%(7)$ & 0.86 \\
\hline MB & $3.5 \%(10)$ & $4.0 \%(5)$ & 0.83 \\
\hline SB & $4.3 \%(12)$ & $2.4 \%(3)$ & 0.37 \\
\hline Stent thrombosis & $1.4 \%(4)$ & $0.0 \%(0)$ & 0.19 \\
\hline
\end{tabular}

Dichotomous data are presented as \% (n).

differences in the clinical outcomes of TVF, TLF, or MACE between the Tryton and PS groups at either 30 days or 1 year of clinical followup. Thus, the study met its primary non-inferiority endpoint with

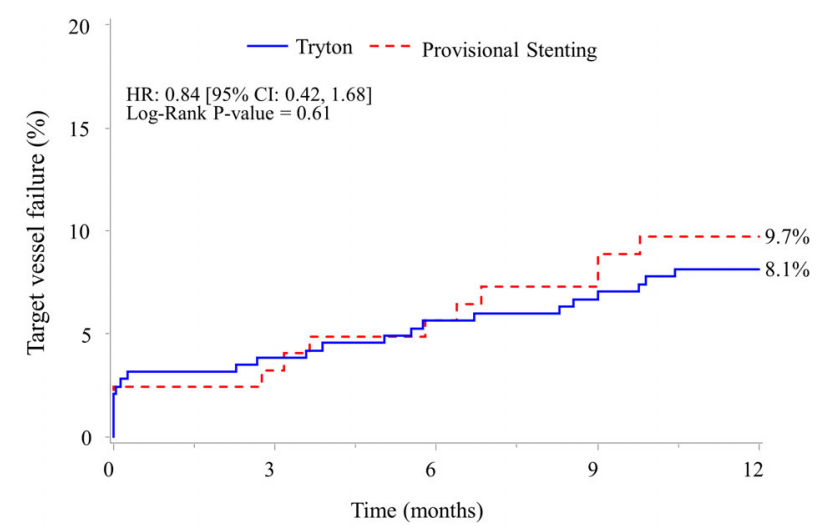

Number at risk:

$\begin{array}{ll}\text { Tryton } & 287 \\ \text { Provisional } & 124\end{array}$ 273
120 265
117 260 204

FIGURE 1 One-year target lesion failure: Tryton versus PS. Abbreviations: $\mathrm{Cl}$, confidence interval; $\mathrm{HR}$, hazard ratio [Color figure can be viewed at wileyonlinelibrary.com]
TABLE 5 Angiographic outcomes at 9 months

\begin{tabular}{|llll|}
\hline & $\begin{array}{l}\text { Pooled Tryton } \\
(\boldsymbol{n}=59)\end{array}$ & PS $(\boldsymbol{n}=73)$ & P value \\
\hline MB & & & \\
\hline $\begin{array}{c}\text { Reference vessel } \\
\text { diameter, mm }\end{array}$ & $3.11 \pm 0.34$ & $2.98 \pm 0.31$ & 0.03 \\
\hline $\begin{array}{c}\text { In-segment MLD } \\
\text { In-stent MLD }\end{array}$ & $2.30 \pm 0.55$ & $2.19 \pm 0.47$ & 0.23 \\
\hline $\begin{array}{c}\text { In-stent diameter } \\
\text { stenosis, \% }\end{array}$ & $13.61 \pm 11.70$ & $15.04 \pm 11.93$ & 0.49 \\
\hline $\begin{array}{c}\text { Binary restenosis } \\
\text { In-segment }\end{array}$ & $8.5 \%(5 / 59)$ & $9.6 \%(7 / 73)$ & 0.82 \\
\hline $\begin{array}{l}\text { In-stent } \\
\text { SB } \quad 3.4 \%(2 / 59)\end{array}$ & $1.4 \%(1 / 73)$ & 0.44 \\
\hline $\begin{array}{c}\text { Reference vessel } \\
\text { diameter, mm }\end{array}$ & $2.47 \pm 0.27$ & $2.45 \pm 0.26$ & 0.66 \\
\hline In-segment MLD & $1.75 \pm 0.56$ & $1.44 \pm 0.42$ & 0.0004 \\
\hline $\begin{array}{c}\text { Diameter stenosis, \% } \\
\text { Binary restenosis }\end{array}$ & $29.34 \pm 21.94$ & $41.14 \pm 17.51$ & 0.0008 \\
\hline $\begin{array}{l}\text { In-segment } \\
\text { In-stent }\end{array}$ & $19.0 \%(11 / 58)$ & $34.2 \%(25 / 73)$ & 0.052 \\
\hline
\end{tabular}

Continuous data are presented as mean \pm SD and dichotomous data as \% $(n / N)$.

respect to TVF at 1 year comparing the Tryton and PS groups. (4) Nine-month follow-up angiographic assessment identified a benefit for the Tryton SB Stent compared with PS with respect to in-segment MLD, DS, and in-segment binary restenosis.

Multiple studies have evaluated the safety and efficacy of a twostent strategy compared with $\mathrm{PS},{ }^{3-8,19}$ and most have failed to show an advantage for a two-stent technique. A meta-analysis incorporating the results of 9 RCTs including 2,569 patients reported that a twostent strategy had similar clinical safety (cardiac death and stent thrombosis) and efficacy (TLR, target vessel revascularization) compared with the PS strategy. Moreover, studies evaluating the performance of dedicated bifurcation devices, such as the BiOSS LIM stent ${ }^{20}$ also showed similar clinical outcomes in comparison to PS approach. ${ }^{21,22}$

A recognized caveat of the 2-stent strategy reflected in the above mentioned and other meta-analyses ${ }^{1,23,24}$ as well as in the TRYTON Pivotal RCT is a higher incidence of MI, in particular PPMI. In this regard, a number of key points should be considered. First, vessel preparation, stenting, and post-dilation of the SB inevitably lead to more vascular injury than PS and thus predispose a patient to PPMI. Second, the definition of PPMI was not consistent throughout the different RCTs included in the various meta-analyses. As a result, the dichotomization of PPMI may have a different impact in each of the trials. Indeed, one of the primary reasons the Tryton Pivotal RCT failed to meet its primary non-inferiority endpoint was an increase in PPMI compared with PS; however, the definition of PPMI in the RCT was a CK-MB $\geq 3 \times$ the upper limit of normal, ${ }^{5,7}$ a clinically outdated definition that has been supplanted by the more contemporary SCAI definition of PPMI. ${ }^{25}$ Indeed, in the current study using the SCAI definition, we found no difference between the Tryton group and the PS group in incidence of PPMI. Nevertheless, it remains unclear whether PPMI, 
and more specifically PPMI from the SB in bifurcation $\mathrm{PCl}$, is associated with clinically significant myocardial damage that impacts TLF.

Another factor that may influence not only the rate of PPMI but also TLF is the diameter of the SB. In the subgroup analysis of patients with large SBs from the meta-analysis mentioned earlier, ${ }^{1}$ PS was associated with higher risk of target vessel revascularization and $M B$ restenosis compared with a two-stent strategy, suggesting a possible advantage to the complex approach in patients with large SBs. Indeed, a recent study identified that $\sim 30 \%$ of first diagonals carry a functional myocardial mass of $\geq 10 \%,{ }^{26}$ equating to a degree of ischemia that may impact cardiac death and $\mathrm{MI}^{27}$ Considering that $72.5 \%$ of patients in the Tryton group in this study involved an LAD diagonal, the benefits of greater procedural success and DS at follow-up could thus have important clinical implications.

Notably, procedure duration was $\sim 12$ min longer, fluoroscopy was $\sim 5.5$ minutes longer, and contrast utilization was $\sim 30 \mathrm{~mL}$ greater in the Tryton group. This could actually be expected when comparing two-stent strategy with PS. Considering that the use of intravascular imaging increases procedure duration by $\sim 15 \mathrm{~min}^{28}$ and that there were no episodes of acute renal failure in the Tryton group, we believe that this finding is probably of limited clinical significance. Moreover, procedural duration and contrast used in the Tryton group were comparable to those reported in other bifurcation studies evaluating two stents techniques.

Several limitations of this study should be acknowledged. First, despite including the initial intended population of the Tryton Pivotal $\mathrm{RCT}$, our study may be subject to selection bias as the study population includes a non-pre-specified subgroup of the RCT as well as patients taking part in the non-randomized Confirmatory Study. Second, the inclusion of patients with $\mathrm{SB} \geq 2.25 \mathrm{~mm}$ according to QCA should be considered as an extrapolation of what should be visually assessed as a $\geq 2.5-\mathrm{mm} \mathrm{SB}$. Third, only short lesions ( $<5 \mathrm{~mm}$ ) with DS $>50 \%$ met the inclusion criteria for the Tryton studies, and whether these conclusions would remain valid with longer lesions or wireassessed physiologically significant disease of the SB requires further investigation. Moreover, the definition of procedural success was based on angiographic assessment of SB residual stenosis. The functional and clinical significance of higher procedural success in the Tryton group according to this definition is not certain. Fourth, while FKB was required per protocol in the PS group, the clinical benefit of such an approach have been recently challenged. ${ }^{29,30}$ Finally, the current version of the Tryton is a bare metal stent; whether a drug-eluting version will increase its beneficial effect remains to be determined.

\section{5 | CONCLUSIONS}

In patients with true bifurcations and large SBs enrolled in the Tryton Pivotal RCT and the Confirmatory Study, treatment with the Tryton SB Stent was associated with non-inferior 1-year clinical outcomes and favorable angiographic results compared with PS.

\section{CONFLICT OF INTEREST}

Philippe Généreux: Speaker's fees - Abbott Vascular, Edwards Lifescience, Medtronic, Tryton Medical Inc., Cardinal Health, and Cardiovascular
Systems Inc., consulting fees - Abbott Vascular, Boston Scientific, Cardiovascular Systems Inc., and Pi-Cardia; institutional research grant - Boston Scientific. Equity - SIG.NUM, SoundBite Medical Solutions Inc., Saranas, and Pi-Cardia. D. Christopher Metzger: Symposium honoraria - Abbott Vascular, Boston Scientific. Ziad A. Ali: Institutional research grants to Columbia University from St. Jude Medical and Cardiovascular Systems Inc.; consultant to St Jude Medical, Acist and Cardinal Health.

\section{ORCID}

Maayan Konigstein (D) https://orcid.org/0000-0002-9398-471X Annapoorna Kini (D) https://orcid.org/0000-0002-7189-3307

\section{REFERENCES}

1. Gao XF, Zhang YJ, Tian NL, et al. Stenting strategy for coronary artery bifurcation with drug-eluting stents: a meta-analysis of nine randomised trials and systematic review. Eurolntervention. 2014;10: 561-569

2. Latib A, Colombo A. Bifurcation disease: what do we know, what should we do? JACC Cardiovasc Interv. 2008;1:218-226.

3. Colombo A, Moses JW, Morice MC, et al. Randomized study to evaluate sirolimus-eluting stents implanted at coronary bifurcation lesions. Circulation. 2004;109:1244-1249.

4. Ferenc $M$, Gick M, Kienzle RP, et al. Randomized trial on routine vs. provisional T-stenting in the treatment of de novo coronary bifurcation lesions. Eur Heart J. 2008;29:2859-2867.

5. Hildick-Smith D, de Belder AJ, Cooter N, et al. Randomized trial of simple versus complex drug-eluting stenting for bifurcation lesions: the British bifurcation coronary study: old, new, and evolving strategies. Circulation. 2010;121:1235-1243.

6. Pan M, de Lezo JS, Medina A, et al. Rapamycin-eluting stents for the treatment of bifurcated coronary lesions: a randomized comparison of a simple versus complex strategy. Am Heart J. 2004;148:857-864.

7. Steigen TK, Maeng M, Wiseth R, et al. Randomized study on simple versus complex stenting of coronary artery bifurcation lesions: the Nordic bifurcation study. Circulation. 2006;114:1955-1961.

8. Chen SL, Santoso T, Zhang JJ, et al. A randomized clinical study comparing double kissing crush with provisional stenting for treatment of coronary bifurcation lesions: results from the DKCRUSH-II (double kissing crush versus provisional stenting technique for treatment of coronary bifurcation lesions) trial. J Am Coll Cardiol. 2011;57:914-920.

9. Colombo A, Bramucci E, Sacca S, et al. Randomized study of the crush technique versus provisional side-branch stenting in true coronary bifurcations: the CACTUS (coronary bifurcations: application of the crushing technique using Sirolimus-eluting stents) study. Circulation. 2009;119:71-78.

10. Chen SL, Ye F, Zhang JJ, et al. Randomized comparison of FFR-guided and angiography-guided provisional stenting of true coronary bifurcation lesions: the DKCRUSH-VI trial (double kissing crush versus provisional stenting technique for treatment of coronary bifurcation lesions VI). JACC Cardiovasc Interv. 2015;8:536-546.

11. Medina A, Suarez de Lezo J, Pan M. A new classification of coronary bifurcation lesions. Rev Esp Cardiol. 2006;59:183.

12. Hildick-Smith D, Behan MW, Lassen JF, et al. The EBC TWO study (European bifurcation coronary TWO): a randomized comparison of provisional T-stenting versus a systematic 2 stent Culotte strategy in large caliber true bifurcations. Circ Cardiovasc Interv. 2016;9:e003643.

13. Chen SL, Zhang JJ, Han Y, et al. Double kissing crush versus provisional stenting for left Main distal bifurcation lesions: DKCRUSH-V Randomized Trial. J Am Coll Cardiol. 2017;70:2605-2617.

14. Genereux P, Kumsars I, Lesiak M, et al. A randomized trial of a dedicated bifurcation stent versus provisional stenting in the treatment of coronary bifurcation lesions. J Am Coll Cardiol. 2015;65:533-543.

15. Genereux P, Kumsars I, Schneider JE, et al. Dedicated bifurcation stent for the treatment of bifurcation lesions involving large side branches: Outcomes from the Tryton Confirmatory Study. JACC Cardiovasc Interv. 2016;9:1338-1346. 
16. Grundeken MJ, Genereux P, Wykrzykowska JJ, Leon MB, Serruys PW. The Tryton side branch stent. Eurolntervention. 2015; 11(Suppl V):V145-V146.

17. Moussa ID, Klein LW, Shah B, et al. Consideration of a new definition of clinically relevant myocardial infarction after coronary revascularization: an expert consensus document from the Society for Cardiovascular Angiography and Interventions (SCAI). J Am Coll Cardiol. 2013; 62:1563-1570.

18. Cutlip DE, Windecker S, Mehran R, et al. Academic research consortium. Clinical end points in coronary stent trials: a case for standardized definitions. Circulation. 2007;115:2344-2351.

19. Katritsis DG, Siontis GC, loannidis JP. Double versus single stenting for coronary bifurcation lesions: a meta-analysis. Circ Cardiovasc Interv. 2009;2:409-415.

20. Gil RJ, Bil J, Grundeken MJ, et al. Regular drug-eluting stents versus the dedicated coronary bifurcation sirolimus-eluting BiOSS LIM(R) stent: the randomised, multicentre, open-label, controlled POLBOS II trial. Eurolntervention. 2016;12:e1404-e1412.

21. Dubois C, Bennett J, Dens J, et al. COmplex coronary bifurcation lesions: RAndomized comparison of a strategy using a dedicated selfexpanding biolimus-eluting stent versus a culotte strategy using everolimus-eluting stents: primary results of the COBRA trial. Eurolntervention. 2016;11:1457-1467.

22. Lesiak M. The need for dedicated bifurcation stents: a critical analysis. Interv Cardiol. 2016;11:124-127.

23. Niccoli G, Ferrante G, Porto I, et al. Coronary bifurcation lesions: To stent one branch or both? A meta-analysis of patients treated with drug eluting stents. Int J Cardiol. 2010;139:80-91.

24. Zhang F, Dong L, Ge J. Simple versus complex stenting strategy for coronary artery bifurcation lesions in the drug-eluting stent era: a meta-analysis of randomised trials. Heart. 2009;95:1676-1681.

25. Moussa ID, Klein LW, Shah B, et al. Consideration of a new definition of clinically relevant myocardial infarction after coronary revascularization: an expert consensus document from the Society for Cardiovascular Angiography and Interventions (SCAI). Catheter Cardiovasc Interv. 2014;83:27-36.

26. Kim HY, Doh JH, Lim HS, et al. Identification of coronary artery side branch supplying myocardial mass that may benefit from revascularization. JACC Cardiovasc Interv. 2017;10:571-581.

27. Shaw LJ, Berman DS, Picard MH, et al. Comparative definitions for moderate-severe ischemia in stress nuclear, echocardiography, and magnetic resonance imaging. JACC Cardiovasc Imaging. 2014;7: 593-604.

28. Ali ZA, Maehara A, Genereux P, et al. Optical coherence tomography compared with intravascular ultrasound and with angiography to guide coronary stent implantation (ILUMIEN III: OPTIMIZE PCI): a randomised controlled trial. Lancet. 2016;388:2618-2628.

29. Niemela $M$, Kervinen $K$, Erglis A, et al. Randomized comparison of final kissing balloon dilatation versus no final kissing balloon dilatation in patients with coronary bifurcation lesions treated with main vessel stenting: the Nordic-Baltic bifurcation study III. Circulation. 2011;123: 79-86.

30. Lassen JF, Holm NR, Banning A, et al. Percutaneous coronary intervention for coronary bifurcation disease: 11th consensus document from the European bifurcation Club. Eurolntervention. 2016;12:38-46.

How to cite this article: Konigstein M, Srdanovic I, Gore AK, et al. Outcomes of the Tryton-dedicated bifurcation stent for the treatment of true coronary bifurcations: Individual-patientdata pooled analysis. Catheter Cardiovasc Interv. 2019;93: 1255-1261. https://doi.org/10.1002/ccd.27952 